\title{
Trichostrongylus vitrinus
}

National Cancer Institute

\section{Source}

National Cancer Institute. Trichostrongylus vitrinus. NCI Thesaurus. Code C125972.

A species of parasitic roundworms in the family Trichostrongylidae that most often infests sheep, goats, camel, deer, and rabbits and are mostly found in the proximal third of the small intestine. 